\title{
Corrosion screening of chamber inhibitors for an aluminum alloy ${ }^{1}$
}

\section{O.A. Goncharova, D.S. Kuznetsov, N.N. Andreev,* Yu.I. Kuznetsov, N.P. Andreeva and S.S. Vesely}

\author{
A.N. Frumkin Institute of Physical Chemistry and Electrochemistry, Russian Academy \\ of Sciences, Leninsky pr. 31, 119071 Moscow, Russian Federation \\ *E-mail: $\underline{\text { n.andreev@mail.ru }}$
}

\begin{abstract}
The chamber method is a version of vapor-phase protection of metals from atmospheric corrosion. In this method, thin adsorption films with long-term protective after-effect are formed on the articles by short-term metal treatment with vapors of low-volatile compounds at elevated temperatures. It is rather a new method. Its theoretical bases have been little developed so far and a search for efficient chamber corrosion inhibitors still remains an empirical process. In this study, a combination of physical (ellipsometry, wetting angle measurements), electrochemical (potentiodynamic anodic polarization, electrochemical impedance spectroscopy) and corrosion methods (tests under recurrent moisture condensation conditions) was used to study the properties of adsorption films formed on aluminum alloy AMg6 by the "chamber" method in vapors of amines (octadecylamine, triethanolamine, tribenzylamine and diaminopropane), heterocyclic compounds (Captax, Altax and 3-aminotriazole), carboxylic acids (stearic, oleic, benzoic, succinic, crotonic, neodecanoic, isophthalic, isonicotinic, linolenic, flufenamic, ascorbic acids and carboxylic acid A), as well as salts of carboxylic acid A (with dimethylaminoethanol, urotropine and dimethylbenzylamine). It has been found that chamber treatment of the alloy with the compounds listed above improve its corrosion resistance in a humid atmosphere, though not efficiently enough. The carboxylic acids themselves are most promising agents, and the optimum temperature of surface treatment by these compounds is $140^{\circ} \mathrm{C}$. One-hour treatment of steel with vapors of oleic or neodecanoic acids or carboxylic acid $\mathrm{A}$ at this temperature creates nano-sized adsorption films on AMg6 alloy. They slightly hydrophilize the surface but possess some protective aftereffect. Further improvement of chamber protection methods for $\mathrm{AMg} 6$ alloy should apparently involve the selection of synergents for carboxylate-type chamber corrosion inhibitors.
\end{abstract}

Key words: vapor-phase metal protection, corrosion inhibitors, chamber inhibitors, aluminum alloy AMg6.

Received: March 9, 2019. Published: March 28, 2019

doi: $\underline{10.17675 / 2305-6894-2019-8-2-7}$

\footnotetext{
${ }^{1}$ This study was financially supported by the Russian Science Foundation (RSF) grant no. 17-13-01413 "Fundamental aspects of formation of ultrathin passivating films from organic compounds in protection from atmospheric corrosion".
} 


\section{Introduction}

Vapor-phase protection of metals is a reliable and cost-effective method for protection from atmospheric corrosion [1-3]. It is based on the use of corrosion inhibitors (volatile VCI [3-7], or chamber inhibitors - ChIn [8-17]) that are adsorbed on a metal from the gas phase.

The theory of metal protection by VCIs is well developed and the improvement of their practical use continues [1-7]. Another variety of vapor-phase protection based on the use of ChIn is a new method called chamber treatment. In this method, thin adsorption films with long-term protective after-effect (PAE) are formed on articles by short-term treatment of the metal with vapors of low-volatile compounds at elevated temperatures.

By raising the metal treatment temperature, it is possible to increase the vapor pressure of organic compounds to a level required for rapid formation of adsorption films. In view of this, low volatile inhibitors unsuitable for traditional vapor-phase protection can be used as ChIn. Examples of this are salts of higher carboxylic acids, octadecylamine and other substances [8-17] previously used only as contact inhibitors.

The PAE of metal treatment with vapors of these compounds can be very high because, in contrast to VCI, the adsorption films of ChIn slowly evaporate from the metal surface in corrosive atmospheres.

However, not all low-volatile inhibitors are promising as ChIn. Though, as the temperature rises, the vapor pressure of inhibitors increases, which favors the adsorption of their vapors, it can decrease the adsorption of vapors on solid sorbents, including the metals. That is why an inhibitor will not always be adsorbed on a metal at a temperature that ensures its high volatility. It is still difficult to predict the efficiency of a ChIn, and we have to admit that the search for efficient ChIn is empirical.

For some metals, the search for organic inhibitors quickly led to the development of efficient $\mathrm{ChIn}$; for others, it turned into a long and laborious process. The latter metals include aluminum and its alloys. For some of them, including AMg6, no efficient ChIn have been found so far. This article is devoted to the analysis of some regularities of chamber protection of AMg6 alloy identified by the authors at the first stage of the search for ChIn, in corrosion and electrochemical studies on the efficiency of organic compounds belonging to various classes.

\section{Experimental}

The experiments were carried out using samples and electrodes made of aluminum alloy AMg6 (GOST 4784-97). Flat specimens had dimensions of $30 \times 50 \times 1 \mathrm{~mm}$. Each specimen had a hole for mounting in test cells and chambers. Cylindrical electrodes were $10 \mathrm{~mm}$ in diameter. One of their butt-ends had a hole with threading for the mounting rod. Electrodes were embedded in Teflon shells in order to prevent the interaction of their side surfaces with the electrolyte during the tests. The lower butt-end of the cylinder served as the working surface. 
Before treatment of specimens and electrodes with ChIn vapors, their working surfaces were cleaned with sandpapers with various grain size, degreased with acetone, and dried. Further, the specimens were mounted in $0.5 \mathrm{~L}$ sealed glass vessels containing a weighed portion of a ChIn $(0.5 \mathrm{~g})$. The vessels were placed into a heated drying chamber. The temperature of the latter was $80,100,120,140$ or $160^{\circ} \mathrm{C}$. The metal treatment time was $1 \mathrm{~h}$. After exposure in the chamber, the vessels were removed, allowed to cool to room temperature and kept for one day. The specimens were then withdrawn and tested.

In the course of corrosion tests with intense condensation of moisture and electrochemical measurements (potentiodynamic and impedance measurements), the protective ability of films formed by chamber treatment of the alloy in vapors of amines (octadecylamine, triethanolamine, tribenzylamine and diaminopropane), heterocyclic compounds (Captax, Altax and 3-aminotriazole), carboxylic acids (stearic, oleic, benzoic, succinic, crotonic, neodecanoic, isophthalic, isonicatinic, linolenic, flufenamic, ascorbic and carboxylic acid A) and salts of carboxylic acid A (with dimethylaminoethanol, urotropine and dimethylbenzylamine) was estimated. All the reagents used in this study were of "pure" grade.

In the tests with recurrent moisture condensation on the specimens, the latter were attached with nylon fibers to the lids of airtight glass cells. The volume of each cell was $600 \mathrm{ml}$. Hot water $\left(50^{\circ} \mathrm{C}, 100 \mathrm{ml}\right)$ was poured into each cell. Once every 24 hours, each cell was opened and the cooled water was replaced with hot water. Water replacement was combined with visual inspection of specimens. The absolute values of the time of corrosion initiation on the alloy treated in ChIn vapors were used as the ChIn efficiency criterion.

The thickness $(d)$ of films formed on the metal under predefined conditions was measured with a manual Gartner ellipsometer with light beam modulation and advanced light detection. An LSM-S-111-10-NNP25 solid-state laser with diode pumping and a wavelength of $540 \mathrm{~nm}$ was used as the radiation source. During the tests, the variation in ellipsometric angles $\Delta$ and $\Psi$ were recorded. The thicknesses of inhibitor and oxide films were calculated using the Ellipsometry Calculation Spreadsheet (E. Kondoh).

The angles of metal surface wetting with distilled water $(\theta)$ were estimated for a droplet $2 \mu \mathrm{l}$ in volume. A droplet was applied on a specimen surface and photographic images were taken with a specialized DCM 300 digital camera. The $\theta$ values were determined in the images using the angle meter available in a graphic editor.

Electrochemical measurements were performed using an IPC-pro potentiostat (RF) and a standard three-electrode cell with divided electrode spaces. A platinum wire served as the auxiliary electrode. Potentials $(E)$ were measured against a saturated silver/silver chloride reference electrode and converted to the normal hydrogen scale. The experiments were carried out in borate buffer solution ( $\mathrm{pH}$ 7.36) containing $0.001 \mathrm{M}$ sodium chloride.

In potentiodynamic experiments, the electrodes were placed into a cell containing the electrolyte, kept for $30 \mathrm{~min}$ and polarized from the established potential $\left(E_{\mathrm{st}}\right)$ in the anodic direction. The potential sweep rate was $0.2 \mathrm{mV} / \mathrm{s}$. The pitting potential $\left(E_{\mathrm{pit}}\right)$ values were 
used as the criterion of the protective effect. This process was detected by a sharp increase in the anodic current density $(i)$ or current oscillations.

Electrochemical impedance spectra were obtained using a potentiostat and a frequency response analyzer (FRA) produced in RF. The electrodes were placed into a cell with the electrolyte and kept for 30 min before the measurements that were performed at the open circuit potential. The measurement frequency range was $0.1-10^{5} \mathrm{~Hz}$.

The electrochemical impedance parameters were calculated using the equivalent circuit shown in Figure 1.

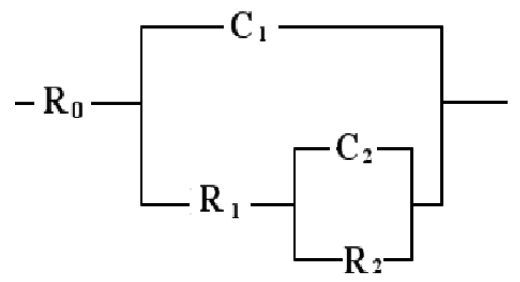

Figure 1. Equivalent circuit used to calculate the impedance parameters.

Here $R_{0}$ is the solution resistance; $C_{1}$ and $R_{1}$ are the capacitance and resistance of the double electric layer, respectively; $C_{2}$ and $R_{2}$ are similar parameters characterizing the oxide and adsorption layers.

The results were processed and impedance parameters were determined using Dummy Circuits Solver software, version 2.1. The fit between the experimental and calculated data was no worse than $98 \%$.

The degree of steel electrode protection was calculated using the formula:

$$
Z=\left(\Sigma R_{\text {inh }}-\Sigma R_{\mathrm{bg}}\right) / \Sigma R_{\text {inh }} \cdot 100 \%
$$

where $R_{\mathrm{bg}}$ and $R_{\text {inh }}$ are the total resistances of "steel-electrolyte" interphase interaction, including $R_{1}$ and $R_{2}$, after thermal treatment of the electrode in the absence and in the presence of a ChIn, respectively.

\section{Experimental results and discussion}

The results of corrosion tests with recurrent moisture condensation on the samples are presented in Table 1. In these tests, we performed the primary selection of ChIn promising for $\mathrm{AMg} 6$ protection. In most cases, the temperature of chamber treatment $\left(t_{\mathrm{CT}}\right)$ was $100^{\circ} \mathrm{C}$. If a compound showed even an insignificant PAE at this $t_{\mathrm{CT}}$, then it was studied at other $t_{\mathrm{CT}}$ values as well.

Samples of the alloy that were not heat-treated started to corrode after 2 days under the experimental conditions. The first signs of corrosion (in the form of pits) on the specimens that were heat-treated at 80 and $100^{\circ} \mathrm{C}$ without a ChIn appeared in 5 days after the start of the test. An increase in $t_{\mathrm{CT}}$ increased the incubation time of corrosion. In the case of treatment at 120,140 and $160^{\circ} \mathrm{C}$, corrosion appeared on the $6^{\text {th }}, 10^{\text {th }}$ and $12^{\text {th }}$ day of testing, respectively. The character of corrosion damage was the same in all these cases. 
None of the tested amines showed apparent protective properties under the conditions studied. At $t_{\mathrm{CT}}$, the corrosion incubation time of the alloy treated with their vapors was the same, within the experimental error, as the time of corrosion initiation on the reference samples.

The heterocyclic compounds studied also proved to have low efficiency. Captax slightly delayed the start of corrosion on the specimens at $t_{\mathrm{CT}}=100$ and $120^{\circ} \mathrm{C}$, but it even stimulated corrosion at high $t_{\mathrm{CT}}$ values. CT of the alloy in Altax and 3-aminotriazole vapors at $100^{\circ} \mathrm{C}$ did not provide any PAE.

Carboxylic acids changed the nature of corrosion from local to general and were usually more efficient. However, benzoic, crotonic, lauric, linolenic, flufenamic, stearic, and ascorbic acids did not form films with PAE after CT at $t_{\mathrm{CT}}=100^{\circ} \mathrm{C}$. Isonicotinic, isophthalic, succinic, oleic, neodecanoic acid, and carboxylic acid A had the best protective ability. In fact, the temperature dependence of the PAE of isophthalic acid had a maximum at $100-120^{\circ} \mathrm{C}$, and those of isonicotinic and succinic acids had a maximum at $100^{\circ} \mathrm{C}$. In these cases, the initiation of corrosion was inhibited no more than 2.5-3 fold.

Previously, we also observed similar extremal dependences of PAE on $t_{\mathrm{CT}}$ on metals [9-17]. They appear due to the interaction of the two processes mentioned in the introduction, which differently affect the adsorption of ChIn vapors. On the one hand, the vapor pressure of inhibitors grows with an increase in $t_{\mathrm{CT}}$, which favors their adsorption. On the other hand, as $t$ rises, the adsorption of vapors on solid sorbents becomes weaker.

OLA, NDA, and CAA showed approximately the same inhibition factor as isophthalic, isonicotinic, and succinic acids. However, the maximum PAE was observed at higher $t_{\mathrm{CT}}$ where the absolute incubation times of the onset of corrosion increased markedly. In fact, the first corrosion damage on alloy samples treated with oleic acid at $140^{\circ} \mathrm{C}$ appeared after 24 days of exposure under corrosive conditions, while in the case of NDA and CAA, after 33 and 50 days, respectively. A calculation of the inhibition factors with respect to samples that were either not heat treated at all or treated with ChIn vapors gives values of $12,16.5$ and 25 for OLA, NDA and CAA, respectively.

One can see that the temperature maximum of PAE was not reached in the case of NDA and CAA. However, increasing the $t_{\mathrm{CT}}$ to $160^{\circ} \mathrm{C}$ resulted in the dropwise condensation of these compounds on the sample surfaces. In view of this, their PAE at this and higher $t_{\mathrm{CT}}$ values was not studied. In contrast to [17] where the PAE of CT increased synergistically on mixing higher carboxylic acids with polyamine A, CAA salts were inferior to the pure acid in all cases.

Thus, corrosion screening of ChIn for aluminum alloy $\mathrm{AMg} 6$ allowed us to select OLA, NDA and CAA as the most promising compounds. The optimum $t_{\mathrm{CT}}$ of the aluminum alloy with these compounds is $140^{\circ} \mathrm{C}$. The properties of adsorption films formed by them from the gas phase under these conditions were studied in more detail. 
Table 1. Effect of the temperature of adsorption film formation on the results of corrosion experiments with moisture condensation on the samples.

\begin{tabular}{|c|c|c|c|c|c|}
\hline \multirow{2}{*}{ ChIn } & \multicolumn{5}{|c|}{ Protection time (days) at $t_{\mathrm{CT}}$ : } \\
\hline & $80^{\circ} \mathrm{C}$ & $100^{\circ} \mathrm{C}$ & $120^{\circ} \mathrm{C}$ & $140^{\circ} \mathrm{C}$ & $160^{\circ} \mathrm{C}$ \\
\hline Without ChIn & 5 & 5 & 6 & 10 & 12 \\
\hline Octadecylamine & - & 5 & - & - & - \\
\hline Triethanolamine & 5 & 6 & 7 & 11 & 12 \\
\hline Tribenzylamine & - & 5 & - & - & - \\
\hline Diaminopropane & - & 5 & - & - & - \\
\hline Captax & - & 7 & 13 & 7 & 6 \\
\hline Altax & - & 5 & - & - & - \\
\hline Aminotriazole & - & 5 & - & - & - \\
\hline Benzoic acid & - & 5 & - & - & - \\
\hline Crotonic acid & - & 5 & - & - & - \\
\hline Lauric acid & - & 5 & - & - & - \\
\hline Linoleic acid (LA) & - & 5 & - & - & - \\
\hline Flufenamic acid & - & 5 & - & - & - \\
\hline Stearic acid & - & 5 & - & - & - \\
\hline Ascorbic acid & - & 5 & - & - & - \\
\hline Succinic acid & 11 & 15 & 5 & 8 & - \\
\hline Isophthalic acid & 8 & 13 & 14 & 12 & - \\
\hline Isonicotinic acid & 11 & 15 & 5 & 5 & - \\
\hline Carboxylic acid A (CAA) & 9 & 11 & 30 & 50 & - \\
\hline Oleic acid (OLA) & 9 & 9 & 18 & 24 & 12 \\
\hline Neodecanoic acid (NDA) & 10 & 18 & 18 & 33 & - \\
\hline $\begin{array}{c}\text { Salt of CAA and } \\
\text { dimethylaminoethanol }\end{array}$ & - & 5 & - & - & - \\
\hline Salt of CAA and urotropine & - & 5 & - & - & - \\
\hline $\begin{array}{c}\text { Salt of CCA and } \\
\text { dimethylbenzylamine }\end{array}$ & - & 8 & 6 & - & - \\
\hline Salt of CCA and triethanolamine & 9 & 12 & 27 & 22 & 18 \\
\hline
\end{tabular}

First of all, using the ellipsometry method, the integral thicknesses $d$ of the surface layers formed on the alloy were measured. Unfortunately, separate measurement of the 
thicknesses $d$ of oxide and adsorption films, like it was done in [12, 13, 15-17], was impossible for $\mathrm{AMg} 6$ alloy due to the closeness of their refractive indexes.

The measurement results shown in Table 2 indicate that at $140^{\circ} \mathrm{C}$, the vapors of OLA, NDA and CAA form ultrathin films on the surface and their $d$ values lie in the range from 13.5 (for CAA) to $24.5 \mathrm{~nm}$ (for NDA). In this case, no correlation is observed between the PAE of films under conditions of recurrent condensation of moisture and their $d$.

Table 2. Effect of CT on the thickness $d$ of surface films and contact angles of wetting of their surface with water.

\begin{tabular}{ccc}
\hline ChIn & $\boldsymbol{d}$ of surface layers, $\mathbf{n m}$ & $\boldsymbol{\theta},^{\circ}$ \\
\hline Without ChIn & 1.5 & 104 \\
OLA & 14.5 & 87 \\
NDA & 24.5 & 77 \\
CAA & 13.5 & 80 \\
\hline
\end{tabular}

It is indicative that these films not only did not hydrophobize the alloy surface but even reduced the contact angles of wetting it with water from $104^{\circ}$ to 87,77 and $80^{\circ}$ for OLA, NDA anc CAA, respectively.

The results of potentiodynamic polarization tests are presented in Figure 2 and Table 2.

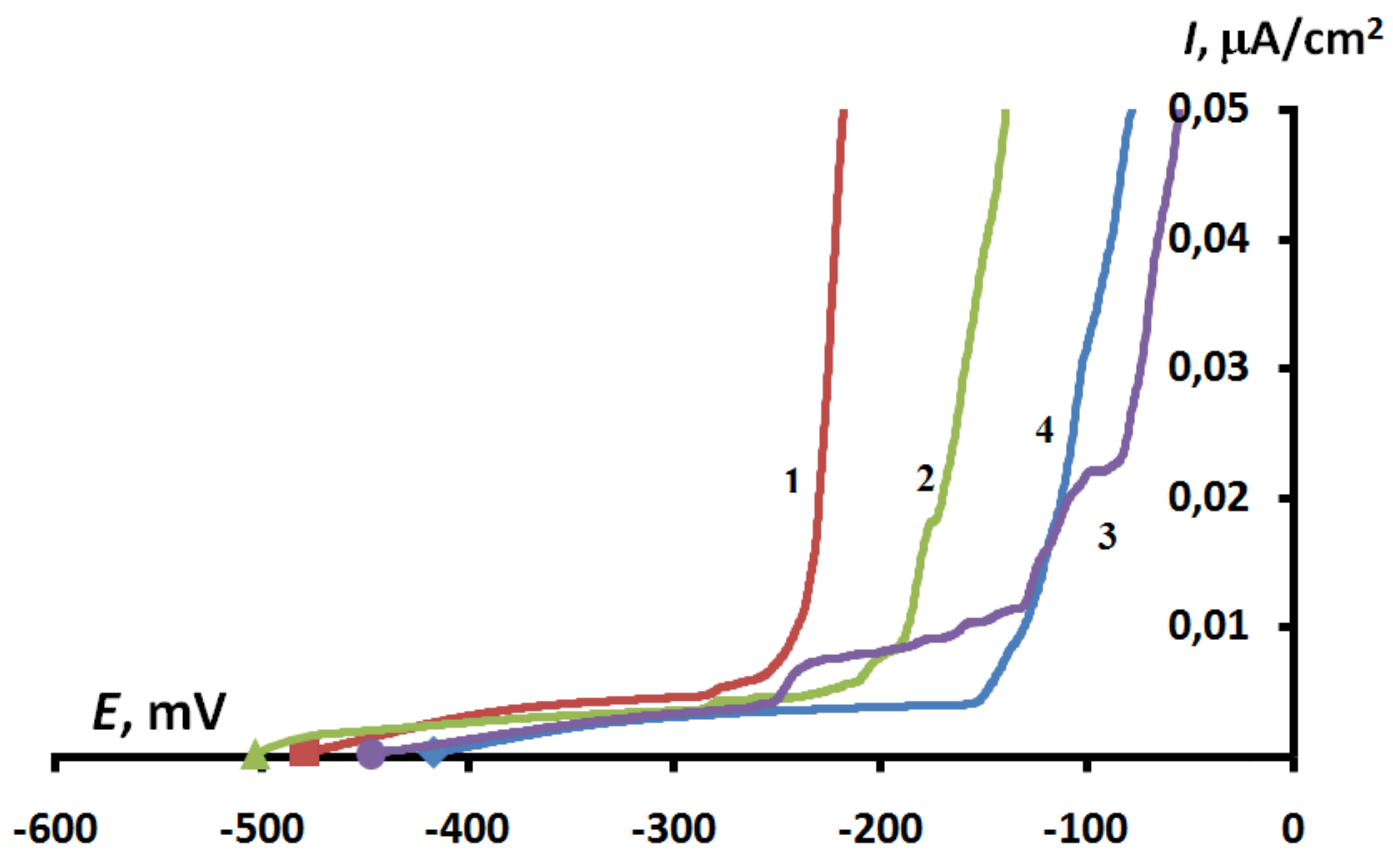

Figure 2. Potentiodynamic polarization curves of $\mathrm{AMg} 6$ electrode after $\mathrm{CT}$ at $140^{\circ} \mathrm{C}$ : 1 -without a ChIn, in the presence of ChIn: 2 - NDA, 3 - CAA, 4 - OLA. 
Table 3. Characteristics of potentiodynamic polarization curves after $\mathrm{CT}$ at $140^{\circ} \mathrm{C}$ without and in the presence of ChIn.

\begin{tabular}{ccc}
\hline ChIn & $\boldsymbol{E}_{\text {start }}, \mathbf{V}$ & $\boldsymbol{E}_{\mathbf{p t}}, \mathbf{V}$ \\
\hline Without ChIn & -0.48 & -0.25 \\
CAA & -0.45 & -0.23 \\
OLA & -0.42 & -0.15 \\
NDA & -0.47 & -0.21 \\
\hline
\end{tabular}

The $E_{\text {start }}$ of the alloy heat treated without a ChIn equals $c a .-0.48 \mathrm{~V}$. All the inhibitors studied ennobled $E_{\text {start }}$, although to a small degree, which is a consequence of some inhibition of the anodic process. OLA caused the largest shift of $E_{\text {start }}$ (by $0.06 \mathrm{~V}$ ), while NDA caused the smallest shift (by $0.01 \mathrm{~V}$ ).

The shape of anodic polarization curves was typical of a passive metal. On scanning the potential $E$ in anodic direction, $i$ oscillations appeared at $E_{\mathrm{pit}}=-0.25 \mathrm{~V}$ after a short passivity region on the polarization curves of the alloy that underwent heat treatment without a ChIn. Inspection of the electrodes indicated their local depassivation: dark spots, i.e., pits visible to the naked eye appeared on the surface. Further anodic polarization was accompanied by an abrupt $i$ increase, i.e., breakdown occurred.

Treatment of the alloy with vapors of the ChIn studied slightly inhibited pitting by ennobling $E_{\text {pit }}$. No significant stabilization of the passive state occurred. In fact, the highest value of $E_{\text {pit }}(-0.15 \mathrm{~V})$ was observed for electrodes treated with OLA vapors, while the smallest value $(-0.23 \mathrm{~V})$, in the case of treatment with CAA vapors. It should be noted that the method of polarization curves, the use of which was justified in studies of ChIn on other metals [9-17], proved to be very drastic for AMg6 and therefore uninformative. In view of this, the PAE of the three selected ChIn was studied by electrochemical impedance. Its spectra are shown in Figure 3 in the form of Nyquist diagrams.

The hodograph of an electrode heat-treated without a ChIn was a slightly distorted semicircle accurately described by the equivalent circuit used (Figure 1). In this case, the calculated $\mathrm{R}_{1}$ and $\mathrm{R}_{2}$ values were 15.7 and $13.8 \mathrm{kOhm} \cdot \mathrm{cm}^{2}$, while those of $C_{1}$ and $C_{2}$ were 3.36 and $19.85 \mu \mathrm{F} / \mathrm{cm}^{2}$, respectively (Table 4 ).

Electrode treatment with a ChIn did not change the shape of the hodographs or the accuracy of their description by the same equivalent circuit. However, the values of its parameters changed markedly: $R_{1}$ and $R_{2}$ increased, while $C_{1}$ and $C_{2}$ decreased. In fact, CT of the alloy in CAA vapors increased $R_{1}$ to 32.3 and $R_{2}$ to $20.9 \mathrm{kOhm} \cdot \mathrm{cm}^{2}$. The values of $C_{1}$ and $C_{2}$ decreased to 2.89 and $6.15 \mu \mathrm{F} / \mathrm{cm}^{2}$, respectively. These changes indicate that corrosion is inhibited approximately 2 -fold, as confirmed by a calculation of $Z(51.3 \%)$. OLA (61.0\%) and NDA (57.9\%) are characterized by similar $Z$ values. 


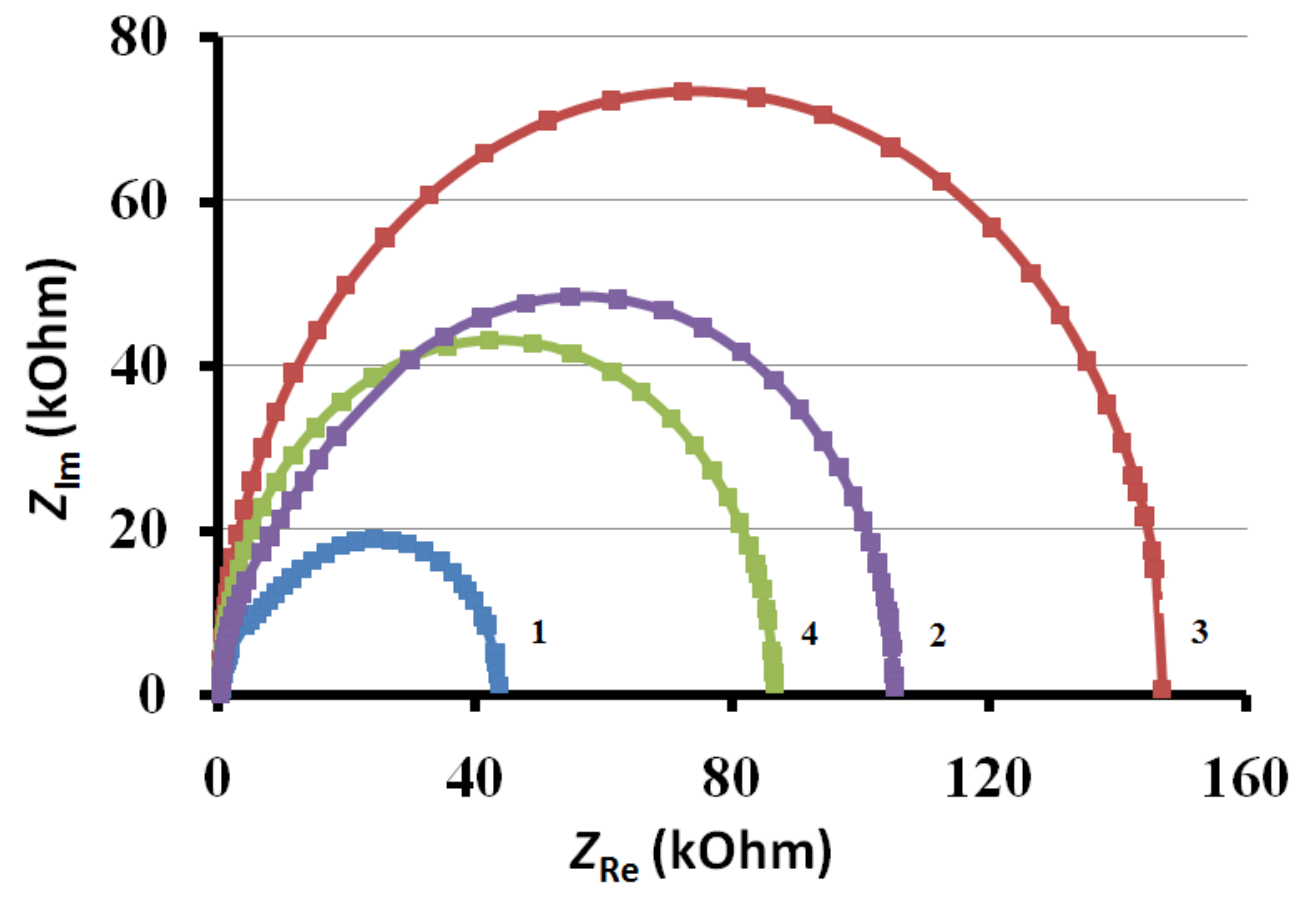

Figure 3. Nyquist plots of the electrode after $\mathrm{CT}$ at $140^{\circ} \mathrm{C}: 1$ - without a ChIn; in the presence of ChIn: 2 - NDA, 3 - CAA, 4 - OLA.

Table 4. Impedance parameters calculated after CT of electrodes without or in the presence of ChIn.

\begin{tabular}{ccccccc}
\hline ChIn & $\begin{array}{c}\boldsymbol{R}_{\mathbf{0}}, \\
\mathbf{k O h m} \cdot \mathbf{c m}^{\mathbf{2}}\end{array}$ & $\begin{array}{c}\boldsymbol{R}_{\mathbf{1}}, \\
\mathbf{k O h m} \cdot \mathbf{c m}^{\mathbf{2}}\end{array}$ & $\boldsymbol{C}_{\mathbf{1}}, \boldsymbol{\mu} \mathbf{F} / \mathbf{c m}^{\mathbf{2}}$ & $\begin{array}{c}\boldsymbol{R}_{\mathbf{2}}, \\
\mathbf{k O h m} \cdot \mathbf{c m}^{\mathbf{2}}\end{array}$ & $\boldsymbol{C}_{\mathbf{2}}, \boldsymbol{\mu \mathbf { F } / \mathbf { c m } ^ { 2 }}$ & $\boldsymbol{Z}, \boldsymbol{\%}$ \\
\hline $\begin{array}{c}\text { Without } \\
\text { ChIn }\end{array}$ & 0.49 & 15.7 & 3.36 & 13.8 & 19.85 & - \\
CAA & 0.48 & 32.3 & 2.89 & 20.9 & 6.15 & 51.3 \\
OLA & 0.49 & 40.3 & 1.60 & 20.5 & 4.70 & 61.0 \\
NDA & 0.50 & 37.4 & 1.75 & 24.8 & 11.8 & 57.9 \\
\hline
\end{tabular}

Thus, carboxylic acids are a promising class of ChIn for aluminum alloy AMg6. Our experience allows us to assume that the efficiency of the studied compounds of this class can be enhanced by further improvement of chamber protection methods for AMg6 alloy, in particular, by choosing synergents.

\section{Conclusions}

1. Although the amines, heterocyclic compounds, as well as salts of carboxylic acids with amines that we studied can somewhat increase the corrosion resistance of AMg6 alloy in a humid atmosphere after chamber treatment, their efficiency is insufficient for using this treatment for the temporary protection of items and semi-finished products made of this aluminum alloy. 
2. One-hour treatment of AlMg6 alloy with vapors of oleic acid, neodecanoic acid and carboxylic acid $\mathrm{A}$ at a temperature of $140^{\circ} \mathrm{C}$ forms a nanosized adsorption film with an appreciable protective aftereffect on its surface.

3. The further improvement of chamber treatment methods for AMg6 alloy is associated with the selection of synergents of carboxylate type for ChIn.

\section{References}

1. A.A. Mikhailov, Yu.M. Panchenko and Yu.I. Kuznetsov, Atmospheric corrosion and protection of metals, 2016, Tambov, Pershina Publishing House, 555 pp. (in Russian).

2. I.L. Rozenfel'd and V.P. Persiantseva, Inhibitors of atmospheric corrosion, Moscow, Nauka, 1985 (in Russian).

3. N.N. Andreev and Yu.I. Kuznetsov, Physicochemical aspects of the action of volatile metal corrosion inhibitors, Russ. Chem. Rev., 2005, 74, no. 8, 685-695. doi: 10.1070/RC2005v074n08ABEH001162

4. S. Koehler and G. Reinhard, VCI containing package material - mode of functioning, Int. J. Corros. Scale Inhib., 2014, 3, no. 4, 286-306. 10.17675/2305-6894-2014-3-4286-306

5. D.M. Bastidas, E. Cano and E.M. Mora, Volatile corrosion inhibitors: a review, AntiCorros. Meth. Mater., 2005, 52, no. 2, 71-77.

6. D. Zhang, Z. An, Q. Pan, L. Gao and G. Zhou, Volatile corrosion inhibitor film formation on carbon steel surface and its inhibition effect on the atmospheric corrosion of carbon steel, Appl. Surf. Sci., 2006, 253, no. 3, 1343-1348.

7. F.A. Ansari, C. Verma, Y.S. Siddiqui, E.E. Ebenso and M.A. Quraishi, Volatile corrosion inhibitors for ferrous and non-ferrous metals and alloys: A review, Int. J. Corros. Scale Inhib., 2018, 7, no. 2, 126-150. doi: 10.17675/2305-6894-2018-7-2-2

8. A.Yu. Luchkin, O.A. Goncharova, N.N. Andreev and Yu.I. Kuznetsov, A new method for protection of metals against atmospheric corrosion, Praktika protivokorrozionnoi zashchity, 2017, no. 4, 7-12 (in Russian).

9. A.Yu. Luchkin, O.A. Goncharova, N.N. Andreev, Yu.I. Kuznetsov and N.P. Andreeva, Copper protection by treatment with vapors of low-volatile inhibitors at elevated temperatures, Korroz.: mater., zashch., 2017, no. 11, 25-31 (in Russian).

10. A.Yu. Luchkin, O.A. Goncharova, N.N. Andreev and Yu.I. Kuznetsov, Steel protection by treatment with vapors of octadecylamine, benzotriazole and their mixture at elevated temperatures, Korroz.: mater., zashch., 2017, no. 12, 20-27 (in Russian).

11. O.A. Goncharova, Yu.I. Kuznetsov, N.N. Andreev, A.Yu. Luchkin, N.P. Andreeva and D.S. Kuznetsov, A new corrosion inhibitor for zinc chamber treatment, Int. J. Corros. Scale Inhib., 2018, 7, no. 3, 340-351. doi: 10.17675/2305-6894-2018-7-3-5 
12. O.A. Goncharova, A.Yu. Luchkin, Yu.I. Kuznetsov, N.N. Andreev, N.P. Andreeva and S.S. Vesely, Octadecylamine, 1,2,3-benzotriazole and a mixture thereof as chamber inhibitors of steel corrosion, Int. J. Corros. Scale Inhib., 2018, 7, no. 2, 203-212. doi: 10.17675/2305-6894-2018-7-2-7

13. O.A. Goncharova, N.N. Andreev, A.Yu. Luchkin,Yu.I. Kuznetsov, N.P. Andreeva and S.S. Vesely, Protection of copper by treatment with hot vapors of octadecylamine, 1,2,3-benzotriazole, and their mixtures, Mater. Corros., 2019, no. 1, 161-168.

14. O.A. Goncharova, A.Yu. Luchkin, Yu.I. Kuznetsov and N.N. Andreev, Vapor-phase protection of zinc from atmospheric corrosion by low-volatile organic inhibitors, Korroz.: mater., zashch., 2018, no. 8, 8-13 (in Russian).

15. O.A. Goncharova, A.Yu. Luchkin, N.N. Andreev, N.P. Andreeva and S.S. Vesely, Triazole derivatives as chamber inhibitors of copper corrosion, Int. J. Corros. Scale Inhib., 2018, 7, no. 4, 657-672. doi: 10.17675/2305-6894-2018-7-4-12

16. Yu. Kuznetsov, O. Goncharova, A. Luchkin, S. Vesely and N. Andreev, Vapor-phase protection of metals from atmospheric corrosion by low-volatile organic inhibitors, Eurocorr 2018, Paper 121167.

17. O.A. Goncharova, A.Yu. Luchkin, Yu.I. Kuznetsov, N.N. Andreev and N.P. Andreeva, Chamber protection of steel by salts of higher carboxylic acids and polyamine, Korroz.: mater., zashch., 2019 (in press) (in Russian). 